The Israeli Journal of Aquaculture IJA.73.2021.1366847, 14 pages

CCBY-NC-ND-4.0 • https://doi .org/10.46989/001c.23507

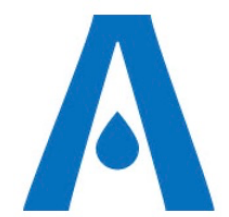

The $I J A$ is a peer-reviewed open-access, electronic journal, freely available without charge to users

Produced by the AquacultureHub non-profit Foundation Sale of $I J A$ papers is strictly forbidden

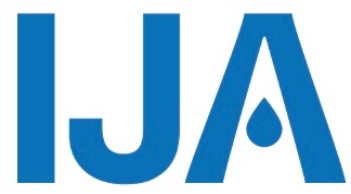

\title{
Dietary conjugated linoleic acid supplementation alleviates high lipid-induced intestinal damage in grass carp (Ctenopharyngodon idella)
}

\author{
Yang Yang ${ }^{1}$, Hongsen $\mathrm{Xu}^{1}$, Jiazhi Chang ${ }^{1}$, Bing $\mathrm{Hu}^{2}$, Jun Liu ${ }^{1}$, Denghang $\mathrm{Yu}^{1}{ }^{1, *}$ \\ ${ }^{1}$ Key Laboratory for Animal Nutrition and Feed Science of Hubei Province, Wuhan \\ Polytechnic University, Wuhan, China
}

${ }^{2}$ Fujian Province Key Laboratory of Special Aquatic Formula Feed, Fuqing, China

Key words: high lipid diets, conjugated linoleic acid, Ctenopharyngodon idella, histomorphology, tight junction, inflammation

\begin{abstract}
High lipid diet has been shown to increase the intestinal permeability and inflammatory properties in mammals, and the conjugated linoleic acid (CLA) could alleviate the symptoms caused by high lipid diet. However, the information about the impact of high lipid diet on the intestine of fish was limited, and the effect of CLA on intestinal changes induced by high lipid diet in fish is still unknown. Therefore, an 8-week feeding trial was conducted to investigate CLA's potential effects against high lipid diet-induced intestinal physical and immune barrier damage in grass carp (Ctenopharyngodon idella). Three isonitrogenous diets, including fish meal-control diet, control diet supplemented with $3.5 \%$ soybean oil as high lipid diet $(\mathrm{HL})$, and $\mathrm{HL}$ replaced with a $2.5 \%$ CLA diet (CLA) formulated. Compared to the control group, $\mathrm{HL}$ significantly increased the expression of pro-inflammation genes (TNF-a, IL-8, IL-1 $\beta$, NF-KB p65, IKBa, IKKa, IKK $\beta$, and IKKY) and downregulated the gene expression of anti-inflammation cytokine (IL-10). The expression of intestinal tight junction proteins (ZO-1, occludin, claudin $\mathrm{c}$, and claudin $b$ ) in fish fed with high lipid diets was lower than those fed with control diets. In the CLA group, the gene expression of pro-inflammation cytokines was decreased, and the expression level of the anti-inflammation cytokine was increased, compared with those in HL group. Moreover, feeding with high lipid diets induced fish intestine and dietary CLA damage could alleviate the symptom as shown by HE staining. In conclusion, this research revealed that CLA could mitigate high lipid diet-induced inflammation and permeability in the intestine of grass carp.
\end{abstract}

* Corresponding author. Professor Denghang Yu, Tel: +86-27-83956175; Fax: +86-2783956175; Email: yudenghang1985@163.com 


\section{Introduction}

The intestine can act as an essential organ for the digestion and absorption of nutrients and play a vital role in preventing the invasion of antigens and pathogens. The intestinal mucosal barriers, such as the immunological and physical barriers, are the essential defensive barriers of gut health in animals (Oshima, 2016). Once the antigens or pathogens invade the portal vein system, the intestinal barrier will be injured, and disordered function manifests as the secretion of inflammatory cytokines and tight junction proteins (TJs) (Dai and Wang, 2015). A high-fat diet has been shown to increase the intestinal permeability and inflammatory properties and disordered intestine function in mammals (Moreira et al., 2012). It is recognized that the effective way to increase intestinal physical barrier function is dietary supplementation with some nutrients through diet.

Inflammation is a complex immune and physiological response to noxious stimuli and pathogens infection. Currently, the inflammation was partly suppressed by down expression of pro-inflammations and increased transcript of anti-inflammations. Conjugated linoleic acid (CLA) is a mixture of positional (e.g., 7,9; 9,11; 10,12;11,13) and geometric (cis or trans) isomers of octadecadienoic acid with a number of biological effects, such as anti-inflammatory and antiadipogenic properties in animal models of disease (Viladomiu et al., 2016). Due to the functional similarity with polyunsaturated fatty acids (PUFA), dietary CLA has been proposed as a novel alternative and complementary intervention capable of regulating inflammation (Xu et al., 1999). Therefore, CLA exhibits the anti-inflammatory capacity in inflammatory-related intestinal diseases and the effect of CLA to alleviate the intestinal damage induced by high lipid diet has received more attention.

The physiological parameters of fish can be assessed by using different techniques. Histological changes of different tissues provide useful information on potential inflammatory reactions and morphological adaptations to assess the dietary modifications (Omne et al., 2015). On the other hand, gene expression profile measured by qRT-PCR allows evaluating various genes involved in different processes (Schmittgen, 2008), including inflammatory processes (cytokines and other pro-inflammatory mediators) and production of intestinal tight junction proteins, giving a comprehensive insight to dietary impact on the intestinal characters. Those techniques were considered as useful tools to investigate the physiological changes in fish induced by HL and CLA diets.

In the present study, grass carp, the third biggest contributor to the world's aquaculture production, was chosen as the experiment species. This research aimed to investigate the effect of a high-fat diet on serum biochemical indices, mRNA expression levels of intestinal inflammatory cytokines and tight junction proteins, and intestinal morphology. Moreover, the potential function of CLA to alleviate the intestinal damage and inflammation induced by high lipid diet was also demonstrated in fish model. To our knowledge, this approach has been rarely conducted.

\section{Materials and Methods}

As shown in Table 1, three isonitrogenous experiment diets were formulated to contain $32.64 \%$ crude protein on a dry matter basis. In the control group, fish meal and casein were used as the primary protein source and supplemented with $2.8 \%$ soybean oil + $1.8 \%$ fish oil. Diet control supplemented with $3.5 \%$ soybean oil was used as high lipid diet $(\mathrm{HL})$. The CLA diet was formulated by adding $3.8 \%$ soybean oil $+1.8 \%$ fish oil + $2.5 \%$ CLA. Feeds were made according to the method reported in detail previously (Luo et al., 2013). Briefly, all ingredients were crushed using a hammer mill (SH1, HosokawaAlpine, Germany) and passed through a 100-mesh screen. Oil, CLA and distilled water $(35 \%, w / w)$ were added to the crushed ingredients and blended homogenous in a Hobart-type mixer (M-256, South China University of Technology, China). Diets were extruded with laboratory presser in the form of $1 \mathrm{~mm}^{-3}$ diameter pellets, dried for about $12 \mathrm{~h}$ in a ventilated oven at $60^{\circ} \mathrm{C}$, and then stored at $-20^{\circ} \mathrm{C}$ before use. 
Table 1 Composition and proximate analyses of the experimental diets ( $100 \mathrm{~g}^{-1}$ of

\begin{tabular}{|c|c|c|c|}
\hline \multirow{2}{*}{ Dietary ingredients (\%) } & \multicolumn{3}{|c|}{ Groups } \\
\hline & Control & $H L$ & $C L A$ \\
\hline Casein & 20 & 20 & 20 \\
\hline Fish meal & 15 & 15 & 15 \\
\hline Cellulose & 6 & 6 & 6 \\
\hline Flour & 24.85 & 21.35 & 21.35 \\
\hline$\alpha$-starch & 25 & 25 & 25 \\
\hline Soybean oil & 2.8 & 6.3 & 3.8 \\
\hline Fish oil & 1.8 & 1.8 & 1.8 \\
\hline Vitamin premix ${ }^{1}$ & 1 & 1 & 1 \\
\hline Mineral premix ${ }^{2}$ & 1 & 1 & 1 \\
\hline Monocalciumphosphate & 2 & 2 & 2 \\
\hline Choline chloride & 0.5 & 0.5 & 0.5 \\
\hline Antioxidant $^{3}$ & 0.05 & 0.05 & 0.05 \\
\hline $\mathrm{CLA}^{4}$ & & & 2.5 \\
\hline \multicolumn{4}{|l|}{ Nutrient level } \\
\hline Crude Protein & $32.64 \%$ & $32.64 \%$ & $32.64 \%$ \\
\hline Crude lipid ${ }^{5}$ & $4.6 \%$ & $8.1 \%$ & $8.1 \%$ \\
\hline Crude ash & $5.95 \%$ & $5.95 \%$ & $5.95 \%$ \\
\hline \multicolumn{4}{|c|}{ 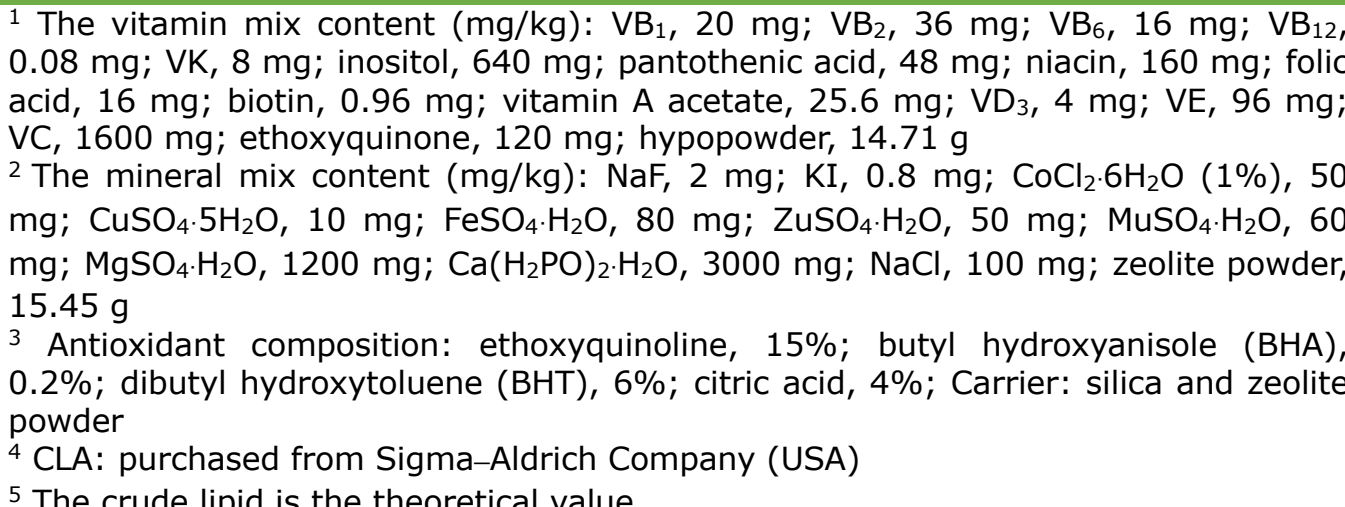 } \\
\hline
\end{tabular}

The disease-free grass carp were purchased from a fish farm in Jiayu, Hubei, China. Two weeks before to the start of the feeding trial, all fish were temporarily cultured in fiberglass cylinders for 14 days and fed the control diet twice a day at 7:30 and 18:00 to acclimate the experimental conditions. Feeding trials were conducted in an indoor recirculating system of Wuhan Polytechnic University. At the beginning of each trial, fish were subjected to fasting for $24 \mathrm{~h}$. Healthy and similarly sized fish ( $\mathrm{n}=900,4.7 \pm 0.05$ g) were randomly selected, batch weighed, and stocked in 9 fiberglass tanks (300 L, 3 tanks/treatment, 100 fish/tank). Each tank was supplied with continuous aeration and maintained the temperature at $25 \pm 0.5^{\circ} \mathrm{C}$. The photoperiod was $12 \mathrm{~L}: 12 \mathrm{D}$ with the light period lasting from 07:00 to 19:00.

At the end of the 8 weeks feeding trial, fish were subjected to fasting for $24 \mathrm{~h}$, anesthetized with MS-222 (Sigma, America) for $15 \mathrm{~min}$. All fish in each cage were captured for measure and dissection. Body weight, liver weight and body length were measured, respectively. The weight gain rate (WGR, \%), specific growth rate (SGR; $\% /$ day), hepatosomatic index (HSI, \%), visceralsomatic index (VSI, \%) and condition factor $\left(\mathrm{CF}, \mathrm{g} / \mathrm{cm}^{3}\right)$ were calculated as follows: (g);

WGR $(\%)=100 \times($ final body weight $(\mathrm{g})-$ initial body weight $(\mathrm{g})) /$ initial body weight 
SGR $(\% / d)=100 \times[($ In (final body weight $(\mathrm{g}))-\ln$ (initial body weight $(\mathrm{g})) / 56$ days];

HSI $(\%)=100 \times$ hepatopancreas weight $(\mathrm{g}) /$ body weight $(\mathrm{g})$;

VSI $(\%)=100 \times$ viscera weight $(\mathrm{g}) /$ body weight $(\mathrm{g})$;

$\mathrm{CF}\left(\mathrm{g} / \mathrm{cm}^{3}\right)=100 \times$ final body weight $(\mathrm{g}) /$ [body length $\left.(\mathrm{cm})\right]^{3}$

Besides, three fish of each group were randomly selected, and the intestinal segments (proximal intestine, PI; mid intestine, MI; distal intestine, DI) were sampled, respectively, and then fixed in $4 \%$ polyoxymethylene for later intestinal morphological analysis. Each segment accounted for approximately $1 / 3$ of the whole intestine. In order to measure the expression of target genes in PI, MI and DI, the segments were sampled from three fish of each group, placed into RNA later (TaKaRa, Dalian, China) at $-80{ }^{\circ} \mathrm{C}$ and used for reverse-transcriptase polymerase chain reaction (qRT-PCR) analysis. Meanwhile, the blood samples were drawn from the caudal vein with a 1-mL syringe. Blood samples were centrifuged $(3,000 \mathrm{~g}$ for $10 \mathrm{~min})$ at $4{ }^{\circ} \mathrm{C}$ to collect the serum and stored at $-80^{\circ} \mathrm{C}$ for future serum biochemical indexes analysis.

The biochemical parameters, including alanine aminotransferase (ALT), alkaline phosphatase (ALP), aspartate aminotransferase (AST), triglycerides (TG), total protein (TP), albumin (ALB), total cholesterol (TC) and lipopolysaccharides (LPS) in serum, were detected by a fully automatic biochemical analyzer (Hitachi, 7100; Japan) using the matching commercial reagent kit (Nanjing Whitman Biotech Co., Ltd). Samples were measured in duplicate.

Total RNA was extracted from the PI, MI and DI of fish using Trizol reagent (Baosheng, Dalian, China), and 1\% denaturing agarose gel electrophoresis was used to analyze the integrity of total RNA. The concentration of RNA was detected with a Nanodrop 8000 Spectrophotometer (Thermo-Fisher Scientific, Waltham, MA, USA). Then, RNA was reversely transcribed to complementary DNA (cDNA) using a Reverse Transcriptase M-MLV kit (TaKaRa) according to the manufacturer's instructions. The specific primers for target genes and housekeeping genes were designed by primer 5.0 software, synthesized by Tsingke (Wuhan, China), and the application efficiency was then assessed. All of the qRT-PCR reactions were run on ABI 7500 real-time PCR system (Applied Biosystems) performed with a SYBR ${ }^{\circledR}$ Premix ExTaq ${ }^{\mathrm{TM}}$ II Kit (Takara, Japan) according to the manufacturer's protocol. The qPCR assays were performed at a volume of $20 \mu \mathrm{L}$, containing $10 \mu \mathrm{L}$ of SYBR Green Master Mix (Takara, Japan), $1 \mu \mathrm{L}$ primer (10 $\mathrm{mM}$ each), $2 \mu \mathrm{L}$ of cDNA template and $6 \mu \mathrm{L}$ of sterile nuclease-free water. The cycling parameters including initial denaturation of $95^{\circ} \mathrm{C}$ for $10 \mathrm{~min}$, followed by 40 cycles of each having denaturation step at $95^{\circ} \mathrm{C}$ for $15 \mathrm{~s}$, annealing and extension at $60{ }^{\circ} \mathrm{C}$ for 1 min. Melt curve analysis of the amplification products were performed at the end of each PCR reaction to confirm that only one PCR product was amplified and detected. Three replicate qPCR analyses were performed per sample. The relative expression of each target gene was determined using the $2^{-\triangle \Delta C T}$ method with $\beta$-actin as the reference gene and the control group as the negative control at each time point. The specific primers used in this study were listed in Table 2.

The PI, MI, and DI segments of intestine were fixed in 4\% polyoxymethylene for 12 h. Segments of the fixed tissues were dehydrated in a series dilution of ethanol solutions, equilibrated in xylene and then embedded in paraffin. Then tissues were processed into approximate $5 \mu \mathrm{m}$ thickness, mounted onto pre-treated slides and stained with hematoxylin and eosin (H\&E). The slides were observed using an imaging microscope (BX60, Olympus, Tokyo, Japan) and photographed by using software (Cellsens standard, Olympus, Tokyo, Japan). The villus height, folds depth and muscularis thickness were measured and analyzed by Image J_v1.8.0 (Wayne Rasband, NIH, USA. http://imagej.nih.gov/ij).

Statistical analysis was performed using Statistical Package for the Social Sciences (SPSS) version 23.0 software for windows (IBM, Armonk, NY, USA). The experimental data were shown as mean \pm standard error (mean $\pm S E M, n=3$ ), and the difference among control, HL and CLA groups in growth performance, gene expression, serum 
biochemical parameters and intestinal morphology were analyzed with one-way analysis of variance (ANOVA), followed by the Duncan's test. The significant difference was defined as $P<0.05$. GraphPad prism 5.0 (GraphPad Software Inc., La Jolla, CA, USA) was employed to plot figures.

Table 2 Primer sequences used for the analysis of mRNA expression by qRT-PCR

\begin{tabular}{|c|c|c|c|c|}
\hline Gene & Primers & Primer sequence $\left(5^{\prime}-3^{\prime}\right)$ & $\begin{array}{l}\text { Product } \\
\text { length } \\
\text { (bp) }\end{array}$ & $\begin{array}{l}\text { GenBank } \\
\text { accession } \\
\text { no. }\end{array}$ \\
\hline \multirow{2}{*}{$\beta$-Actin } & $\beta$-Actin-F & GGCTGTGCTGTCCCTGTA & 18 & \multirow{2}{*}{ M25013 } \\
\hline & $\beta$-Actin-R & GGGCATAACCCTCGTAGAT & 19 & \\
\hline \multirow{2}{*}{ PPAR Y } & PPAR $Y-F$ & GGCTITGTCAACCTGGACTTG & 21 & \multirow{2}{*}{ EU847421.1 } \\
\hline & PPAR $Y-R$ & ATGAGCGTGCCGTCTTTGT & 19 & \\
\hline \multirow{2}{*}{ IFN-Y2 } & IFN-Y2-F & TTACTGCATITGGGTGGTTAAGAG & 24 & \multirow{2}{*}{ FJ766439 } \\
\hline & IFN-Y2-R & AACCTACAGACCAGACATTTTCCA & 24 & \\
\hline \multirow{2}{*}{ TNF-a } & TNF-a-F & TCCAATTACAAGCTGGAGACAAAC & 24 & \multirow{2}{*}{ HQ696609 } \\
\hline & TNF-a-R & TTACAGAGCAAACACCCCAAAA & 22 & \\
\hline \multirow{2}{*}{ IL-1 $\beta$} & 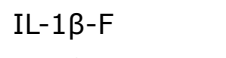 & ATTGGAAATGTGGAGGCATTCT & 22 & \multirow{2}{*}{ JQ692172 } \\
\hline & $\mathrm{IL}-1 \beta-\mathrm{R}$ & AGCAССТСТTCTTCAССАААСТC & 23 & \\
\hline \multirow{2}{*}{ IL-8 } & IL-8-F & GATCCTTGCCAAGTAAGTGTCAATA & 25 & \multirow{2}{*}{ JN663841 } \\
\hline & IL-8-R & GTCCAGATATTCATGGTGCTTTG & 23 & \\
\hline \multirow{2}{*}{ IL-10 } & IL-10-F & GCAAGTCTGAATGTTGCTCATTTGT & 25 & \multirow{2}{*}{ HQ388294 } \\
\hline & IL-10-R & GTCGTCATTGGACTCATAAAACCTC & 25 & \\
\hline \multirow{2}{*}{ NF-KB P65 } & NF-KB P65-F & CGACTGCAAACACAAAACAACC & 22 & \multirow{2}{*}{ KJ526214 } \\
\hline & NF-KB P65-R & TGATGGACACCTGGAAACACA & 21 & \\
\hline \multirow{2}{*}{ IkB a } & IkB a-F & CСTCAACATACAGAACAACCAGAGA & 25 & \multirow{2}{*}{ KJ125069.1 } \\
\hline & IkB a-R & CAGTCATCCACCAGAGAAGCA & 21 & \\
\hline \multirow{2}{*}{ IKK a } & IKK a-F & CGCTITCCACTCACСТTCC & 20 & \multirow{2}{*}{ KM279718.1 } \\
\hline & IKK a-R & ТTСААТССТССТССССТСТGТ & 21 & \\
\hline \multirow{2}{*}{ IKK $\beta$} & IKK $\beta-F$ & ATTCACAGAGACCTCAAACCAGAAA & 25 & \multirow{2}{*}{ KP125491 } \\
\hline & IKK $\beta-R$ & AGCGTCCCAACAAACGATG & 19 & \\
\hline \multirow{2}{*}{ Claudin b } & Claudin b-F & TTCATCATAGCTGGGTTGCTGT & 22 & \multirow{2}{*}{ KF193860 } \\
\hline & Claudin b-R & СТСTCTCTTCTGTGCTGCGTTC & 22 & \\
\hline \multirow{2}{*}{ Claudin C } & Claudin C-F & CAGTCTTGCAGCTTATTCCTGTGT & 24 & \multirow{2}{*}{ KF193859 } \\
\hline & Claudin C-R & ACAGCGATGCTCCTATTTCCA & 21 & \\
\hline \multirow{2}{*}{ Claudin 3} & Claudin 3-F & AAGAGAGATCGGGGCATCAA & 20 & \multirow{2}{*}{ KF193858 } \\
\hline & Claudin 3-R & САTTCTCGGTGGATTGTACTTCTTC & 25 & \\
\hline Claudin 12 & Claudin $12-\mathrm{F}$ & CCCTGAAGTGCCCACAA & 17 & KF998571 \\
\hline Clacumit 12 & Claudin $12-\mathrm{R}$ & GCGTATGTCACGGGAGAA & 18 & 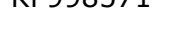 \\
\hline Claudin 15a & Claudin $15 a-F$ & TGCTTIATTCTTGGCTTTC & 19 & KF193857 1 \\
\hline & Claudin $15 a-R$ & CTCGTACAGGGTTGAGGTG & 18 & \\
\hline $70-1$ & $\mathrm{ZO}-1-\mathrm{F}$ & GAACAАССАТСАТСТСТTСАССАС & 24 & \\
\hline$\angle U-1$ & ZO-1-R & АCCATCTGCCTTGCCCTCT & 19 & KJ00005s \\
\hline Occludin & Occludin-F & TGCCATTAAAACCCGTCAAA & 20 & KF193855 \\
\hline 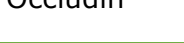 & Occludin-R & TCAGGGACGCCATTCACA & 18 & KFI93050 \\
\hline
\end{tabular}

\section{Results}

The growth performance and morphological indices of grass carp fed with control, $\mathrm{HL}$, and CLA diets for 8 weeks are shown in Table 3. Results showed that fish-fed HL and CLA diets manifested significantly lower WGR and SGR than those of fish fed control diet $(P<0.05)$. Besides, in contrast to the fish-fed HL diet, a fish-fed CLA diet alleviated WGR and SGR's lower symptoms. The results of morphological indices evidenced that HSI, VSI, and CF of fish fed control diet were significantly lower than those of fish fed $\mathrm{HL}$ and 
CLA diets $(P<0.05)$, while no significant difference of HSI and CF were observed in fish fed with HL and CLA diets. Interestingly, the VSI in fish fed with CLA diets showed a significant increase compared with those in the $\mathrm{HL}$ group $(P<0.05)$.

Table 3 Growth performance and morphology indices

\begin{tabular}{llll}
\hline \multirow{2}{*}{ Items } & \multicolumn{3}{c}{ Groups } \\
\cline { 2 - 4 } & Control & $H L$ & $C L A$ \\
\hline IBW(g) & $2.15 \pm 0.2$ & $2.03 \pm 0.17$ & $1.99 \pm 0.04$ \\
FBW(g) & $21.1 \pm 0.98^{\mathrm{b}}$ & $12.05 \pm 2.04^{\mathrm{a}}$ & $9.95 \pm 0.77^{\mathrm{a}}$ \\
WGR(\%) & $735.21 \pm 94.94^{\mathrm{b}}$ & $484.36 \pm 41.7^{\mathrm{a}}$ & $541.79 \pm 135.8^{\mathrm{a}}$ \\
SGR(\%/day) & $2.52 \pm 0.14^{\mathrm{b}}$ & $2.1 \pm 0.09^{\mathrm{a}}$ & $2.2 \pm 0.24^{\mathrm{a}}$ \\
HSI(\%) & $1.24 \pm 0.04^{\mathrm{a}}$ & $1.54 \pm 0.03^{\mathrm{b}}$ & $1.42 \pm 0.1^{\mathrm{b}}$ \\
VSI(\%) & $10.7 \pm 0.1^{\mathrm{a}}$ & $11.68 \pm 0.64^{\mathrm{b}}$ & $10.99 \pm 0.59^{\mathrm{a}}$ \\
CF(g/cm3) & $1.2 \pm 0.08^{\mathrm{a}}$ & $1.54 \pm 0.09^{\mathrm{b}}$ & $1.55 \pm 0.03^{\mathrm{b}}$ \\
\hline
\end{tabular}

* In the same line, values with different letter means significant difference $(P<$ $0.05)$.

The results of serum biochemical parameters were listed in Table 4. When fish were fed with high lipid diet, the levels of TG and LPS and the activity of the AST, ALT and ALP in serum were observed to be significantly higher $(P<0.05)$ than those of fish fed with the control diet. However, TP and ALB content showed a significant decrease $(P<0.05)$ in the $\mathrm{HL}$ group, compared with the control group. Interestingly, TP concentration in fish fed with CLA supplemented diet was significantly higher $(P<0.05)$ than those of fish fed high lipid diet. A significant increase $(P<0.05)$ of ALP activity and TG concentration was detected in fish from the CLA group compared with those of the HL group. Furthermore, no statistically significant changes in the concentration of ALB, TC, and LPS, and ALB and AST activities were observed between fish from HL with CLA group.

Table 4 Serum biochemical parameters of blood in control, HL and CLA groups, respectively

\begin{tabular}{llll}
\hline \multirow{2}{*}{ Items } & \multicolumn{3}{c}{ Groups } \\
\cline { 2 - 4 } & Control & $H L$ & $C L A$ \\
\hline TP $(\mathrm{g} / \mathrm{dL})$ & $296.33 \pm 17.24^{\mathrm{b}}$ & $261.67 \pm 9.87^{\mathrm{a}}$ & $334.33 \pm 18.15^{\mathrm{c}}$ \\
ALB (g/dL) & $117.33 \pm 2.08^{\mathrm{b}}$ & $107.33 \pm 2.3^{\mathrm{a}}$ & $126.33 \pm 8.96^{\mathrm{bc}}$ \\
AST (U/L) & $48 \pm 6.93^{\mathrm{a}}$ & $91.33 \pm 7.57^{\mathrm{c}}$ & $58 \pm 6.56^{\mathrm{ab}}$ \\
ALT (U/L) & $5.67 \pm 0.58^{\mathrm{a}}$ & $11.67 \pm 2.08^{\mathrm{b}}$ & $8.67 \pm 0.58^{\mathrm{ab}}$ \\
ALP (U/L) & $233 \pm 7^{\mathrm{a}}$ & $395.67 \pm 26.41^{\mathrm{b}}$ & $268 \pm 36.37^{\mathrm{a}}$ \\
TC (mg/dL) & $2.44 \pm 0.12^{\mathrm{ab}}$ & $2.86 \pm 0.25^{\mathrm{bc}}$ & $2.26 \pm 0.07^{\mathrm{a}}$ \\
TG (mg/dL) & $3.57 \pm 0.23^{\mathrm{a}}$ & $5.7 \pm 0.35^{\mathrm{b}}$ & $3.53 \pm 0.15^{\mathrm{a}}$ \\
LPS (UE/mL) & $0.016 \pm 0.002^{\mathrm{a}}$ & $0.028 \pm 0.004^{\mathrm{b}}$ & $0.026 \pm 0.01^{\mathrm{ab}}$ \\
\hline
\end{tabular}

* In the same line, values with different small letter superscripts mean significant difference $(P<0.05)$.

The mRNA expression levels of inflammation-related genes in the PI, MI, and DI of grass carp intestine were shown in Figure 1A, Figure 1B, and Figure 1C, respectively. Briefly, in the PI of grass carp (Figure 1A), the gene expression of IKKa, IKK $\beta$, IKKY, NF-KB p65, IL-1 $\beta$, IL-8 and TNF-a in the HL group were up-regulated significantly $(P<$ $0.05)$, and the gene expression of IKBa and PPAR-Y were down-regulated significantly $(P$ $<0.05)$, compared with the control group. Moreover, the mRNA levels of IKK $\beta, N F-K B$ 
p65, IL-1 $\beta$, IL-8 and TNF- $a$ in the CLA group were decreased significantly $(P<0.05)$, and the gene expression of PPAR- $\gamma$ and IL-10 in the CLA group was remarkably enhanced ( $P$ $<0.05)$, compared with those in the $\mathrm{HL}$ group.

In the MI of the fish (Figure 1B), compared with the control group, the gene expression of IKKa, IKK $\beta$, IKKY, NF-KB p65, IL-1 $\beta$, IL-8, and TNF-a were remarkably enhanced $(P<0.05)$, and the gene expression of IKBa PPAR- $\gamma$ and IL-10 were significantly down-regulated $(P<0.05)$ in $\mathrm{HL}$ group. However, in the CLA group, the gene expression of IKKa, IKKY, NF-KB p65, IL-1 $\beta$, IL-8, and TNF-a were significantly decreased $(P<0.05)$, and the gene expression of PPAR- $\gamma$ and IL-10 was increased significantly $(P<0.05)$, compared with the HL group.

In the DI of grass carp (Figure 1C), the mRNA expression levels of IKKa, IKK $\beta$, NFKB p65, IL-1 $\beta$, IL-8, and TNF-a were significantly higher $(P<0.05)$ in fish fed with high lipid diets, compared to fish fed with the control diet. Conversely, the gene expression of IKBa, IL-10, and PPAR-y were significantly lower $(P<0.05)$ in the $\mathrm{HL}$ group compared to the control group. Moreover, the expression of IKKa, IKK $\beta, N F-K B$ p65, IL-1 $\beta$, IL-8, and TNF-a in the CLA group was decreased significantly $(P<0.05)$, and the gene expression of PPAR-Y and IL-10 in the CLA group was remarkably enhanced $(P<0.05)$, compared with those in $\mathrm{HL}$ group.

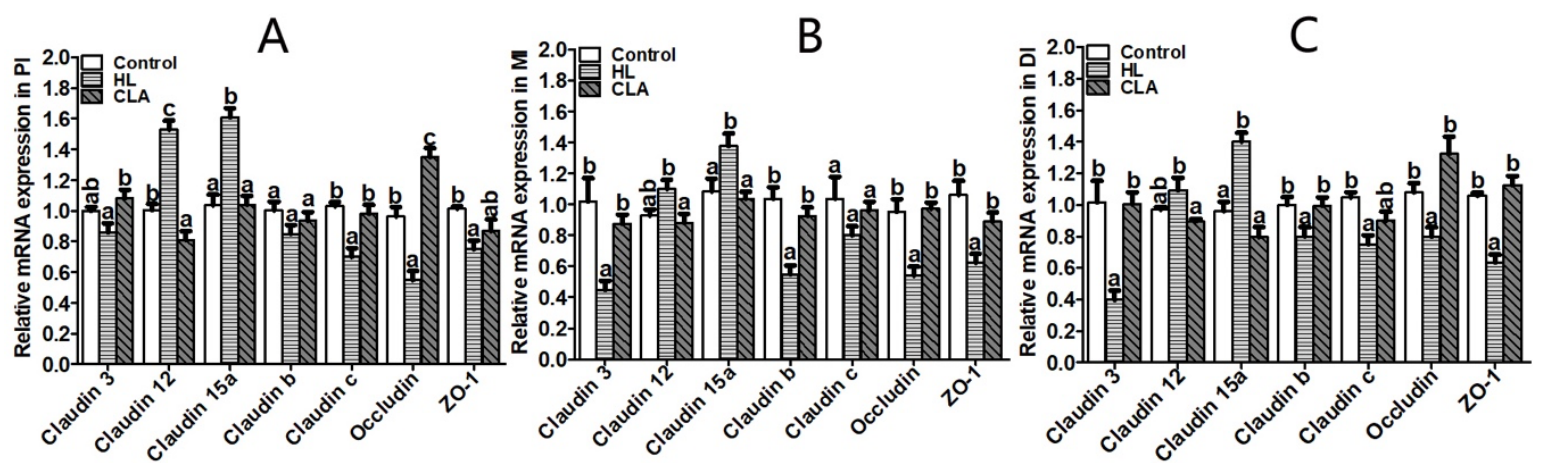

Figure 1 The relative expression of ZO-1, occludin, claudin c, claudin b, claudin 3, claudin $15 a$ and claudin 12 in the PI (A), MI (B) and DI (C) of grass carp (Ctenopharyngodon idella). Data were expressed as means $\pm \operatorname{SEM}(n=3)$, and values not sharing same letters were significantly different $(P<0.05)$. Abbreviation: ZO-1, Zonula occludens-1; PI, proximal intestine; MI, middle intestine; DI, distal intestine.

The mRNA expression levels of tight junction protein-related genes in the PI, MI, and DI of grass carp intestine were shown in Figure 2A, Figure 2B, and Figure 2C, respectively. Compared with the control group, the gene expression of claudin 15a and claudin 12 showed a significant increase $(P<0.05)$ in the HL group, and the gene expression of ZO-1, occluding, and claudin $\mathrm{c}$ showed a significant decrease $(P<0.05)$ in the HL group. Compared with the HL group, the gene expression of occluding, claudin 3 , and claudin $\mathrm{c}$ showed a significant increase $(P<0.05)$ in the CLA group. Interestingly, the expression of claudin 15a and claudin 12 in grass carp fed with CLA diet was significantly reduced $(P<0.05)$ as compared to fish fed with high lipid diet. (Figure 2A)

In the MI of grass carp, feeding with high lipid diet results in significantly higher $(P<$ $0.05)$ claudin 15 a transcription level and remarkable lower $(P<0.05)$ claudin 3 , claudin $b$, claudin $c, Z O-1$, and occluding mRNA level compared to the control diet. Also in fish from the CLA group, there were significantly reduced $(P<0.05)$ between the levels of claudin 12 and claudin 15a, and remarkably improved $(P<0.05)$ between the levels of claudin 3, claudin b, ZO-1, and occluding in comparison of $\mathrm{HL}$ group fed with high lipid diet. (Figure 2B)

In the DI of grass carp, the expression of claudin 15a in the high lipid treatment group was significantly elevated $(P<0.05)$ and the expression of claudin 3 , claudin $b$, claudin $\mathrm{C}, \mathrm{ZO}-1$, and occluding significant decreased $(P<0.05)$, compared with those from the control group. However, treatment with CLA diet, the expression of claudin 12 
and claudin 15 a exhibited a significant decrease $(P<0.05)$, and the expression of claudin 3 , claudin b, ZO-1, and occluding showed a significant increase $(P<0.05)$ as compared with fish fed with high lipid diet. (Figure 2C)

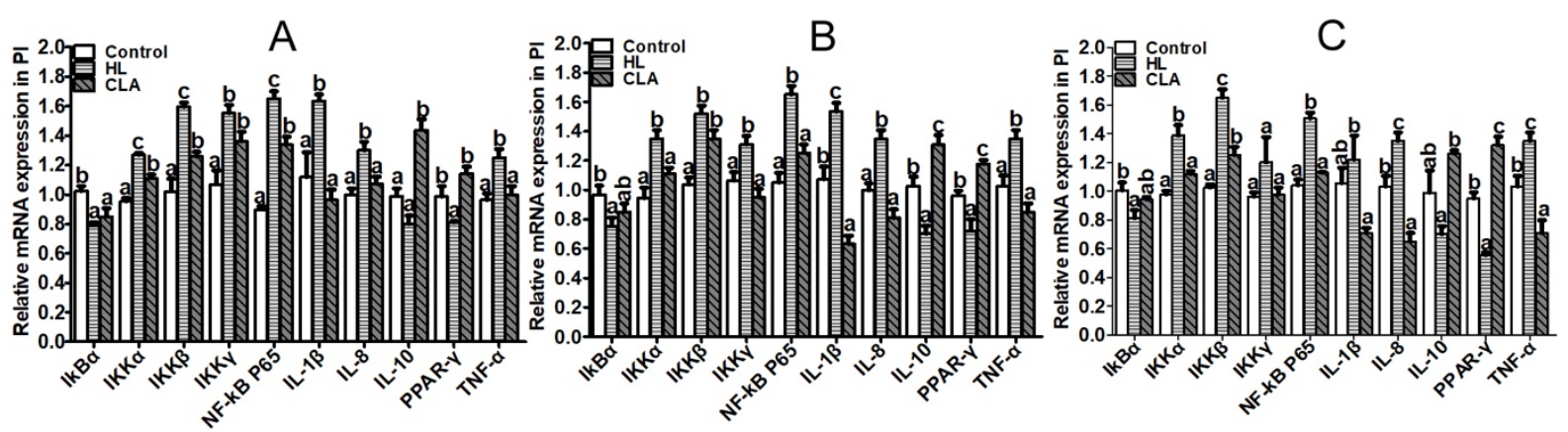

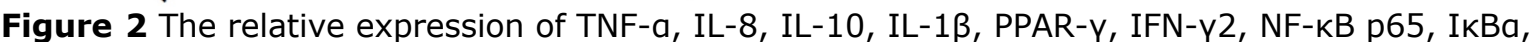
IKKa, IKK $\beta$ and IKKY in the PI, MI and DI of grass carp (Ctenopharyngodon idella). Values were expressed as means $\pm \operatorname{SEM}(n=3)$, and values not sharing same letters were significantly different $(P<0.05)$. Abbreviation: TNF-a, tumor necrosis factor- $a$; IL-8, interleukin-8; IL-10, interleukin-10; IL-1 $\beta$, nterleukin-1beta; PPAR- $\gamma$, proliferator-activated receptor- $\gamma ;$ IFN- $\gamma 2$, interferon gamma 2; NF-KB p65, nuclear factor kappa-light-chain-enhancer of activated B cells 065 subunit; IKBa, NFkappa-B inhibitor subunit alpha; IKKa, inhibitor of nuclear factor kappa-B kinase subunit alpha; IKK $\beta$, inhibitor of nuclear factor kappa-B kinase subunit beta; IKKY, inhibitor of nuclear factor kappa-B kinase subunit gamma.

The mechanical barrier of the intestinal epithelium was detected by HE staining and analyzed by Image J_v1.8.0. HE staining revealed that feeding grass carp with high lipid diet result in apparent damage (arrowhead indicate marked intestinal wall thickening, villi adhesion, and detachment due to inflammatory edema) in PI, MI, and DI of fish, compared with those from control and CLA groups (Figure 3). As shown in Table 5, compared with the control group, the intestinal fold depth in the PI and DI were significant increase $(P<0.05)$ in the HL group. Besides, fish-fed dietary CLA had significantly lower $(P<0.05)$ villi length in PI and significantly higher $(P<0.05)$ muscle thickness in MI compared to those in fish fed the high lipid diets. 

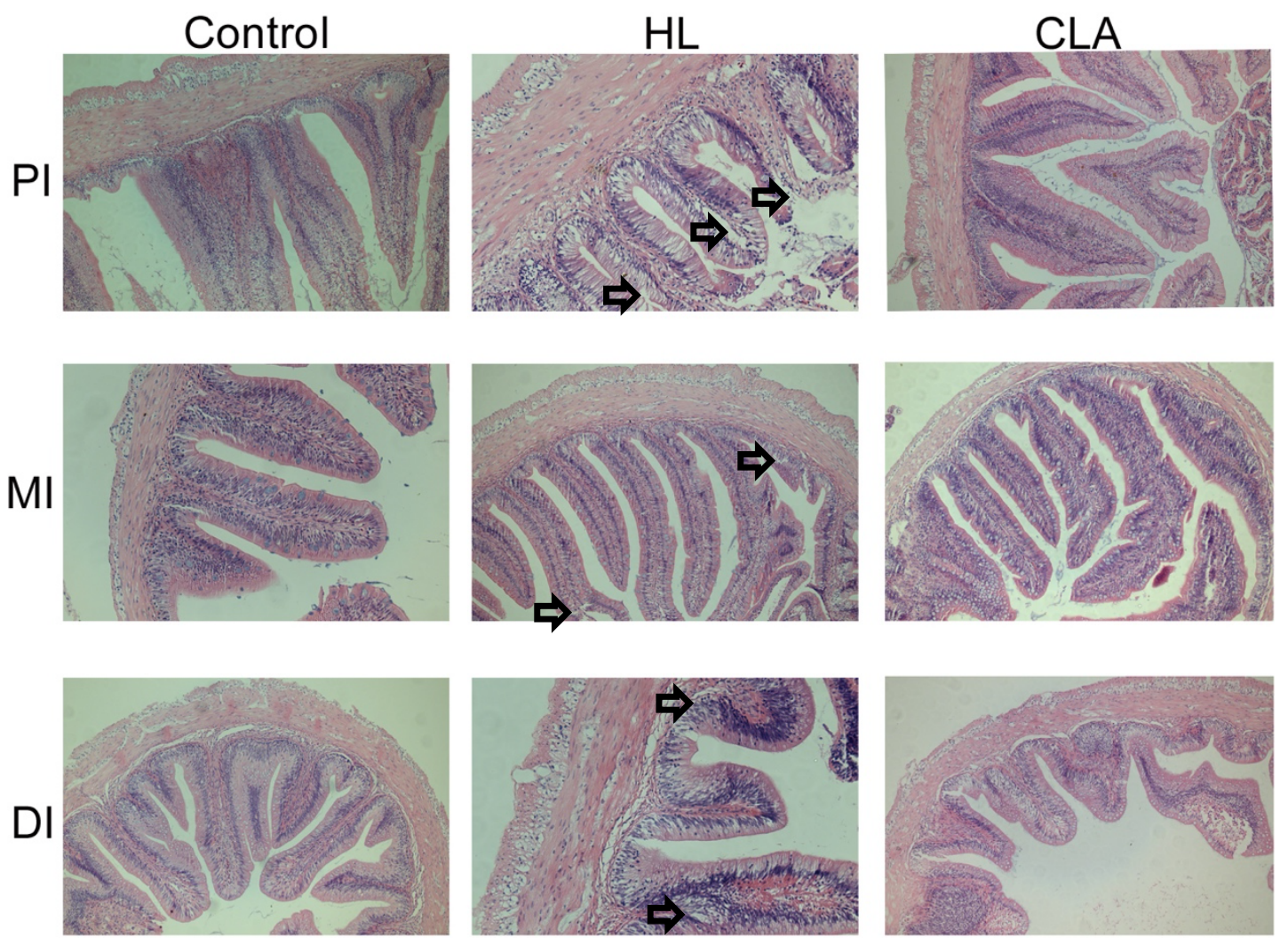

Figure 3 Representative photographs of the histological morphology sections in the PI, MI and DI of grass carp by H\&E staining (magnification, $\times 40$ ). Arrowhead indicate marked intestinal wall thickening, villi adhesion, and detachment due to inflammatory edema.

Table 5 Dietary effect on the histomorphology of the PI, MI and DI of grass carp

\begin{tabular}{lllll}
\hline \multirow{2}{*}{ Items } & & \multicolumn{3}{c}{ Groups } \\
\cline { 3 - 5 } & & Control & $H L$ & CLA \\
\hline \multirow{2}{*}{ PI $(\mu \mathrm{m})$} & Villi length & $660.62 \pm 168.23^{\mathrm{a}}$ & $859.23 \pm 28.75^{\mathrm{a}}$ & $679.33 \pm 25.17^{\mathrm{a}}$ \\
& Muscle thickness & $193.33 \pm 32.15^{\mathrm{b}}$ & $176.67 \pm 11.55^{\mathrm{b}}$ & $173.33 \pm 30.55^{\mathrm{b}}$ \\
& Folds depth & $593.32 \pm 231.8^{\mathrm{a}}$ & $910.00 \pm 26.46^{\mathrm{b}}$ & $563.13 \pm 23.09^{\mathrm{a}}$ \\
& Villi length & $460.37 \pm 57.74^{\mathrm{a}}$ & $670.27 \pm 52.92^{\mathrm{b}}$ & $613.21 \pm 36.06^{\mathrm{ab}}$ \\
MI $(\mu \mathrm{m})$ & Muscle thickness & $156.67 \pm 5.77^{\mathrm{ab}}$ & $110.11 \pm 10.47^{\mathrm{a}}$ & $185.14 \pm 11.85^{\mathrm{b}}$ \\
& Folds depth & $620.81 \pm 103.92^{\mathrm{ab}}$ & $646.75 \pm 56.86^{\mathrm{b}}$ & $433.31 \pm 37.86^{\mathrm{b}}$ \\
& Villi length & $313.33 \pm 95.04^{\mathrm{a}}$ & $433.33 \pm 35.12^{\mathrm{a}}$ & $370.41 \pm 45.83^{\mathrm{a}}$ \\
DI $(\mu \mathrm{m})$ & Muscle thickness & $176.67 \pm 23.09^{\mathrm{b}}$ & $163.73 \pm 45.09^{\mathrm{ab}}$ & $133.33 \pm 58.59^{\mathrm{ab}}$ \\
& Folds depth & $186.67 \pm 73.71^{\mathrm{a}}$ & $313.71 \pm 47.26^{\mathrm{b}}$ & $323.53 \pm 15.28^{\mathrm{b}}$ \\
\hline
\end{tabular}

* In the same line, values with different small letter superscripts mean significant difference $(P<0.05)$.

\section{Discussion}

Blood biochemical indices are essential that can reveal the physiological status and metabolic level of fish. The ALT and AST, critical amino acid transaminases, are widely distributed in animal cytoplasm and mitochondria, play a vital role in the protein metabolism of aquatic animals, and usually use as sensitive makers of tissue function (Pan et al., 2005). The alteration in the activities of tissue marker enzymes, such as ALT, $A S T$, and ALP, is directly related to the degree of organ-specific cell damage (Khandan- 
Barani et al., 2019). ALP is supposed to be connected with some metabolic functions, such as growth, cell differentiation, protein synthesis, uptake and transport of nutrients, and immune capacity (Chen et al., 2019). In this research, we observed that feeding with high lipid diet-induced a significant increase of AST, ALT, and ALP levels in the serum of fish, whereas these levels decreased in the CLA group. ALB and TP play many critical physiological functions associated with body impairment and chronic gastrointestinal disease, respectively (Xie et al., 2015). In the present research, it was found that the levels of ALB and TP in the serum of the HL group were significantly lower $(P<0.05)$ than those of the control group, and CLA could alleviate the symptom induced by high lipid. TG and TC's content in the blood reflects the lipid metabolism and health status in the body. In this research, dietary high lipid diet-induced increased TG, and TC concentration in serum and CLA supplements maintain them average. Similar results were observed for TC and TG in mice (Huang et al., 2017).

The intestinal tract is the body's digestive organ and a significant barrier for the body to resist exogenous substances. The intestinal physical barrier mainly consists of intestinal epithelial cells and tight junction protein. The intestinal mucus layer, which covers the intestinal epithelial cells and the tight junction protein, promotes the mechanical epithelial barrier, consequently playing an essential role in keeping the barrier integrity and function. The tight junction, which relates to selective paracellular permeability between intestinal epithelial cells, is composed of the transmembrane proteins (including occluding and claudins), as well as the intracellular proteins (for example, zonula occludens (ZO)) (Noda et al., 2012). Also, the defect of tight junction barriers can destruct and destroy the gut epithelial barrier function, regulating the pathogenesis of many intestinal diseases (Turner, 2009). Occludin has been considered as an essential component in the maintenance of epithelial integrity and in the accommodation of permeability and other properties of the intestinal physical barrier, being an integrity indicator of the tight junction between the enterocytes, and its' down expression suggested deficiencies in the regulation of the gut inflammatory response (Estruch et al., 2018). Evidence displayed that decreased expression of occludin claudin b, claudin c, claudin 3, and ZO-1 reflect the destruction of an intestinal barrier for teleost fish (Günzel and Alan, 2013). The current study showed that feeding fish with a high diet significantly down-regulated $(P<0.05)$ the expression of ZO-1, occludin, claudin $\mathrm{C}$, claudin $b$, and claudin 3 in the intestine. However, the transcription level of $\mathrm{ZO}-1$, occludin, claudin c, claudin b, and claudin 3 were increased with CLA supplementation in the intestine for grass carp. The results revealed that the fish intestine would be injured by feeding with high lipid diets, and supplementation CLA alleviates high lipid-induced intestinal permeability. Besides, in vertebrates, increased expression of claudin 12 and claudin 15 reflects the disruption of intestinal barrier function (Günzel and Alan, 2013). Interestingly, high lipid diet increased claudin 12 and claudin 15 expression, and CLA decreased the expression, suggesting that high lipid diet disturbed intestinal barrier function for fish through up-regulating claudin 12 and claudin 15 expression, and CLA could repair the intestinal damage induced by high lipid diet.

CLA shows anti-inflammatory characters by inhibiting the expression of lipopolysaccharide-induced cyclooxygenase- 2 by decreasing the release of prostaglandin E2 and the secretion of pro-inflammatory cytokines (Li et al., 2005). Also, dietary CLA contributes to alleviating inflammatory and mucosal damage in the intestine (MacDonald, 2000). The function of the intestinal immune barrier is regulated by a class of cytokines secreted by immune cells. Inflammatory cytokines are considered to consist of proinflammatory and anti-inflammatory cytokines. Fast et al. (2007) reported that the increased expression of a pro-inflammatory cytokines (TNF-a, IL-1 $\beta$, and IL-8), and the decreased expression of an anti-inflammatory cytokines (IL-10 and TGF $\beta$ ), indicated the initiate the inflammatory process. Consistent with previous studies (Kong et al., 2019), the grass carp fed with high lipid diets showed pro-inflammatory effect on the three intestinal segments via enhancing expression of IL-8, TNF- $a$, and IL-1 $\beta$, and decreasing the IL-10 expression. However, supplementation of CLA alleviates the pro-inflammatory 
symptom induced by high lipid diets. Similar results were observed that CLA could regulate the immune reaction and prevent immune-induced symptoms by affecting the generation of inflammatory molecules in mice and domestic animals (Oleszczuk et al., 2012). The potential effect of CLA to alleviate inflammation response was partly dependent activated transcription factors that regulate the transcription of genes related to immune response (O'Shea et al., 2004). CLA, the potent affinity ligands and activators of PPARs, induced accumulation of PPAR-responsive genes (Belury et al., 2002). When activated, PPARs and the retinoid $X$ receptor will bind to PPAR response elements to decrease or increase the expression of genes involved in lipid metabolism and immune response (Yessoufou et al., 2009). Primarily, the activation of PPARY serves as a negative regulator of inflammatory reactions by different mechanisms. The methods contain the gene expression administration of cytokines, chemokines, and the regulation of proinflammatory transcription factors (NF-KB and STAT). In our research, significant downregulation of PPARY transcription in CLA-fed fish was detected compared to those from $\mathrm{HL}$ groups. The results revealed that dietary CLA activated the expression of PPARY, which subsequently binds to DNA and accommodates gene expression of antiinflammatory cytokines, thus leading to the inhibition of colonic inflammation.

Previous research revealed that TNF- $a$ and IL- $1 \beta$ could strengthen the inflammatory reaction by increasing the recruitment and initiation of other inflammatory elements, leading to higher production and release of inflammatory mediators. Moreover, those cytokines have been demonstrated to be involved in regulating tight junction protein transcription (Capaldo and Nusrat, 2009). In Caco-2 cells, researchers indicated that TNF-a decreased the expression of ZO-1 and occludin, respectively (Al-Sadi and Ma, 2007). Also, IL-8 decreased the transcription level of occludin, claudin-5 and ZO-1 in human (Yu et al., 2013). In the present study, the expression of IL-8 and TNF-a showed an opposite trend to the expression occludin, claudin and ZO-1 in the fish intestine, revealing that the change of occludin, claudin and ZO-1 expression may be ascribed to the regulation of TNF- $a$ and IL-8 in the fish intestine. However, the underlying mechanism requires more study.

Furthermore, CLA-initiated PPARY in vitro binds to and uppresses NF-KB activation and translocations into the nucleus in a similar way as the inhibitor of NF-kappa-B inhibitor (IKB). Therefore, this receptor decreased NF-KB-initiated pro-inflammatory cytokine production (Clarke et al., 2010). The TLR4/NF-KB signaling pathways were reported to moderate inflammatory cytokines' secretion (Rebl et al., 2010). In this study, we showed that the transcription levels of TLR4/NF-KB signaling-related genes (such as IKKa, IKK $\beta$, IKKY and NF-KB p65) were significantly increased $(P<0.05)$ in three intestinal segments of grass carp fed with high lipid diets. However, those genes' mRNA expression levels were decreased significantly $(P<0.05)$ in fish fed with CLA diet. These results indicated that NF-KB p65 regulated the expression profile of IL-1 $\beta$, and IL-8, and TNF- $\mathrm{a}$ in the PI, MI, and DI of fish. In a previous study, researchers suggested that IKBa kinases (IKKa, IKK $\beta$ and IKKY) could control NF-KB signaling pathway (Rupa et al., 2010). Here, we found that high lipid diets increased transcription of IL-1 $\beta$, IL-8, and TNF-a and CLA decreased those genes expression levels partly owe to up-regulated or down-regulated expression of IKKa, IKK $\beta$ and IKKY, which play roles in the regulation of IKBa phosphorylation and NF-KB p65 nuclear translocation in the PI and MI of fish.

Histopathology is a valuable tool to display the histological changes in the organs induced by different treatments. In this research, we employed this technique to reveal the histopathological damage disturbed by high lipid diets and prove the potential function of CLA to alleviate high lipid-induced intestine injury. The results suggested that fish fed with high lipid diets increased the fold depth and villi length compared to other groups. It was well known that intestinal villi and folds depth provide a wide surface area for absorption, and an increase in villus length indicates a higher ability to absorb nutrients (Daniels et al., 2010). The tendency of fold depth and villi length in fish fed with high lipid diets was possibly due to the increased lipid metabolism. 


\section{Acknowledgements}

This study was supported by the National Natural Science Foundation of China (grant no. 31902389) and Fujian Province Key Laboratory of Special Aquatic Formula Feed (grant no. TMKJZ1706 and TMKJZ1912).

\section{References}

Al-Sadi, R., and Ma, T., 2007. IL-1b causes an increase in intestinal epithelial tight junction permeability. J Immunol 178(7): 4641-4649. https://doi.org/10.4049/jimmunol.178.7.4641

Belury, M., Moya-Camarena, S., Lu, M., Shi, L., Blanchard, S., 2002. Conjugated linoleic acid is an activator and ligand for peroxisome proliferator-activated receptorgamma (PPARy). Nutr Res 22: 817-824. https://doi.org/10.1016/S02715317(02)00393-7

Capaldo, C., and Nusrat, A., 2009. Cytokine regulation of tight junctions. Biochim Biophys Acta-Biomembr 1788: 864-871. https://doi.org/10.1016/j.bbamem.2008.08.027

Chen, X., Zhao, W., Xie, S., Xie, J., Zhang, Z., Tian, L., Niu, J., 2019. Effects of dietary hydrolyzed yeast (Rhodotorula mucilaginosa) on growth performance, immune response, antioxidant capacity and histomorphology of juvenile Nile tilapia (Oreochromis niloticus). Fish \& Shellfish Immunology 90: 30-39. https://doi.org/10.1016/j.fsi.2019.03.068

Clarke, G., Fitzgerald, P., Hennessy, A., Cassidy, E., Quigley, E., Ross, P., Stanton, C., Cryan, J., Dinan, T., 2010. Marked elevations in pro-inflammatory polyunsaturated fatty acid metabolites in females with irritable bowel syndrome. J Lipid Res 51(5): 1186-1192. https://doi.org/10.1194/jlr.P000695

Dai, X., and Wang, B., 2015. Role of gut barrier function in the pathogenesis of nonalcoholic fatty liver disease. Gastroenterol Res Pract 2015: 1-5. https://doi.org/10.1155/2015/287348

Daniels, C., Merrifield, D., Boothroyd, D., Davies, S., Factor, J., Arnold, K., 2010. Effect of dietary Bacillus spp. and mannan oligosaccharides (MOS) on European lobster (Homarus gammarus L.) larvae growth performance, gut morphology and gut microbiota. Aquaculture 304(1-4): 49-57. https://doi.org/10.1016/j.aquaculture.2010.03.018

Estruch, G., Collado, M., Monge-Ortiz, R., Tomás-Vidal, A., Jover-Cerdá, M., Peñaranda, D., Pérez-Martínez, G., Martínez-Llorens, S., 2018. Long-term feeding with high plant protein-based diets in gilthead seabream (Sparus aurata, L.) leads to changes in the inflammatory and immune related gene expression at intestinal level. BMC Vet Res 14: 1-15. https://doi.org/10.1186/s12917-018-1626-6

Fast, M., Johnson, S., Jones, S., 2007. Differential expression of the pro-inflammatory cytokines IL-1ß-1, TNFa-1 and IL-8 in vaccinated pink (Oncorhynchus gorbuscha) and chum (Oncorhynchus keta) salmon juveniles. Fish \& Shellfish Immunology 22(4): 403407. https://doi.org/10.1016/j.fsi.2006.06.012

Günzel, D., and Alan, S., 2013. Claudins and the modulation of tight junction permeability. Physiol Rev 93: 525-569. https://doi.org/10.1165/ajrcmb.13.1.7541221

Huang, Y., Lin, Z., Ron, H., Hao, M., Da, S., Li, S., Wen, X., 2017. Effects of conjugated linoleic acid on growth, body composition, antioxidant status, lipid metabolism and immunity parameters of juvenile Chu's croaker, Nibea coibor. Aquac Res 49: 546-556. https://doi.org/10.1111/are.13486

Khandan-Barani, H., Gharaei, A., Sanchooli, N., Miri, M., 2019. Blood biochemistry fluctuations as influenced by feed provision in juvenile Snow trout (Schizothorax zarudnyi). Iran J Fish Sci 18: 735-744. https://doi.org/10.22092/ijfs.2019.118286

Kong, L., Cheng, S., Xiang, X., Liu, W., Yu, D., Yang, Y., Zhou, J., Huang, F., Dong, G., 2019. Dietary conjugated linoleic acid modulates morphology, selective immune parameters, and gene expressions in the intestine of grass carp. Fish \& Shellfish Immunology 86: 536-548. https://doi.org/10.1016/j.fsi.2018.11.071 
Li, G., Barnes, D., Butz, D., Cook, M., 2005. 10T, 12C-Conjugated Linoleic Acid Inhibits Lipopolysaccharide-Induced Cyclooxygenase Expression in Vitro and in Vivo. J Lipid Res 46: 2134-2142. https://doi.org/10.1194/jlr.M500064-JLR200

Luo, L., 2013. Comparison of chelated zinc and zinc sulfate as zinc sources for growth and immune response of shrimp (Litopenaeus vannamei). Aquaculture 406-407: 79-84. https://doi.org/10.1016/j.aquaculture.2013.04.026

MacDonald, H., 2000. Conjugated Linoleic Acid and Disease Prevention: A Review of Current Knowledge. J Am Coll Nutr 19: 111S-118S. https://doi.org/10.1080/07315724.2000.10718082

Moreira, A., Texeira, T., Ferreira, A., Peluzio, M., Alfenas, R., 2012. Influence of a high-fat diet on gut microbiota, intestinal permeability and metabolic endotoxaemia. $\mathrm{Br} \mathbf{J}$ Nutr 108: 801-809. https://doi.org/10.1017/S0007114512001213

Noda, S., Tanabe, S., Suzuki, T., 2012. Differential effects of flavonoids on barrier integrity in human intestinal Caco-2 cells. J Agric Food Chem 60: 4628-4633. https://doi.org/10.1021/jf300382h

Oleszczuk, J., Oleszczuk, L., Siwicki, A., Skopińska-Rózewska, E., 2012. Biological effects of conjugated linoleic acids supplementation. Pol J Vet Sci 15: 403-408. https://doi.org/10.2478/v10181-012-0063-x

Omnes, M., Silva, F., Moriceau, J., Aguirre, P., Kaushik, S., Gatesoupe, F., 2015. Influence of lupin and rapeseed meals on the integrity of digestive tract and organs in gilthead seabream (Sparus aurata L.) and goldfish (Carassius auratus L.) juveniles. Aquac Nutr 21: 223-233. https://doi.org/10.1111/anu.12162

O'Shea, M., Bassaganya-Riera, J., Mohede, I., 2004. Immunomodulatory properties of conjugated linoleic acid. The American journal of clinical nutrition 79: 1199-1206. https://doi.org/10.1556/AAlim.33.2004.2.12

Pan, L., Wu, Z., Zhang, H., 2005. Effects of heavy metal ions on transaminases activities of Litopenaeus vannamei. J Ocean Univ 35: 107-195. https://doi.org/10.1360/biodiv.050121

Rebl, A., Goldammer, T., Seyfert, H., 2010. Toll-like receptor signaling in bony fish. Vet Immunol Immunopathol 134: 139-150. https://doi.org/10.1016/j.vetimm.2009.09.021

Rupa, Srivastava., Brandon, J., Burbach., Yoji, Shimizu., 2010. NF-kB Activation in $T$ Cells Requires Discrete Control of IKB Kinase $a / \beta$ (IKKa/ $\beta$ ) Phosphorylation and IKKY Ubiquitination by the ADAP Adapter Protein. Journal of Biological Chemistry 285(15): 11100-11105. https://doi.org/10.1074/jbc.M109.068999

Schmittgen, T., and Livak, K., 2008 Analyzing real-time PCR data by the comparative CT method. Nat Protoc 3: 1101-1108. https://doi.org/10.1038/nprot.2008.73

Turner, J., 2009. Intestinal mucosal barrier function in health and disease. Nat Rev Immunol 9: 799-809. https://doi.org/10.1038/nri2653

Viladomiu, M., Hontecillas, R., Bassaganya-Riera, J., 2016. Modulation of inflammation and immunity by dietary conjugated linoleic acid. Eur J Pharmacol 785: 8795. https://doi.org/10.1016/j.ejphar.2015.03.095

Xie, M., Xu, X., Wang, Y., Liu, Y., 2015. Spectroscopic study on the interaction of 4, 5, 7-trihydroxydihydroflavonoids with human serum albumin. J Chem 63: 2055-2062. https://doi.org/10.1088/1009-0630/7/5/006

Xu, H., Lambert, M., Montana, V., Parks, D., Blanchard, S., Brown, P., Sternbach, D., Lehmann, J., Wisely, G., Willson, T., 1999. Molecular recognition of fatty acids by peroxisome proliferator-activated receptors. Mol Cell 3: 397-403. https://doi.org/10.1016/S1097-2765(00)80467-0

Yessoufou, A., Atègbo, J., Attakpa, E., Hichami, A., Moutairou, K., Dramane, K., Khan, N., 2009. Peroxisome proliferator-activated receptor-a modulates insulin gene transcription factors and inflammation in adipose tissues in mice. Mol Cell Biochem 323: 101-111. https://doi.org/10.1007/s11010-008-9968-1 
Yu, H., Huang, X., Ma, Y., Min, G., Liu, X., 2013. Interleukin-8 regulates endothelial permeability by down-regulation of tight junction but not dependent on integrins induced focal adhesions. Int J Biol Sci 9: 966-979. https://doi.org/10.7150/ijbs.6996 